Revista Energia na Agricultura

ISSN 1808-8759

\title{
OBTENÇÃO DE MASSA DE MANDIOCA COM ADIÇÃO DE MALTODEXTRINA DE AMIDO DE MILHO WAXY. ${ }^{1}$
}

ADRIANA LIMA MORO² \& CLÁUDIO CABELLO ${ }^{3}$

RESUMO: Este trabalho teve como objetivo o desenvolvimento de massa alimentícia a base de mandioca com adição de maltodextrina de amido de milho waxy, como alternativa ao mercado de semi-prontos. O delineamento experimental foi em blocos inteiramente casualizados, em esquema fatorial 4x7, com três repetições. Os tratamentos foram constituídos pela combinação de concentrações de maltodextrina adicionadas à massa de mandioca (0, 5, 10 e 15\% sobre peso seco), com o tempo de armazenamento $(0,2,4,6$, 8, 10 e 12 dias após o preparo), e em duas condições de estocagem (temperatura ambiente e refrigerado). A variedade escolhida para o processamento foi a IAC 576-70. Os dados foram submetidos a análise de variância. As médias foram comparadas pelo teste de Tukey a 5\%. O teor de maltodextrina de amido de milho waxy a $15 \%$ mostrou-se eficaz ao controle do aumento da textura. A massa alimentícia de mandioca com adição de maltodextrina (waxy) é um produto de fácil elaboração, apresentando viabilidade para ser produzida em escala industrial.

Palavras-chave: Semi-pronto, IAC 576-70, textura.

\footnotetext{
${ }^{1}$ Parte da dissertação da $1^{\text {a }}$ autora intitulada: Obtenção de massa de mandioca com adição de maltodextrtina de amido de milho waxy.

${ }^{2}$ Aluna do curso de PG Energia na Agricultura-FCA/UNESP, - Fazenda Experimental Lageado, Rua José Barbosa de Barros - 1780, Caixa Postal - 237 Botucatu-SP - Brasil; CEP 18610-307 email: drymoro@fca.unesp.br

${ }^{3}$ Prof. Dr. CERAT-UNESP, Fazenda Experimental Lageado, Rua José Barbosa de Barros - 1780, Caixa Postal - 237, Botucatu-SP - Brasil, CEP 18610-307. e-mail: dircerat@fca.unesp.br
} 


\section{OBTENTION MASHED OF CASSAVA (MANIHOT ESCULENTA C.) WITH ADDITION OF MALTODEXTRIN OF STARCH OF CORN WAXY.}

SUMMARY: This study aimed to the development of cassava mashed with added maltodextrin of waxy maize starch as an alternative to the semi-ready product. The experimental design was completely randomized using blocks in $4 x 7$ factorial, with three replications. The treatments were the combination of maltodextrin concentrations added in the cassava mass $(0,5,10$ and $15 \%$ on dry weight) with storage time (0, 2, 4, 6, 8, 10 and 12 days after preparation) and two condition (environment and refrigerated temperature). The variety chosen to the processing was the IAC 576-70. The data were subjected to variance analysis. The means were compared by Tukey test at 5\%. The content of maltodextrin from waxy maize starch to $15 \%$ was effective in controlling the increase of texture. The mass of cassava with the addition of maltodextrin showed to be product of easy preparation, showin IAC 576-70g viability to be produced in industrial scale.

Keywords: Semi-ready, IAC 576-70, texture.

\section{INTRODUÇÃO}

A mandioca constitui uma das mais importantes fontes de alimento para as populações de baixa renda do mundo tropical. A mandioca é uma cultura basicamente produtora de carboidratos, que são armazenados nas raízes, aos quais representam o principal valor econômico da planta e, em vários paises é tida como um alimento predominante na dieta diária. Segundo Cuenca e Mandarino (2006) existem atualmente no Brasil 38 milhões de hectares ocupados com culturas anuais, dos quais cerca de 26,79 milhões são destinados a mandioca. Seu cultivo é realizado em todo o território nacional, com a utilização das mais variadas tecnologias.

Segundo Bezerra (2002a) em termos nutricionais, a mandioca pode ser considerada primariamente como uma fonte de energia barata que contribui para a nutrição dos consumidores, os quais necessitam de outros alimentos como fontes de proteínas, vitaminas, minerais e gorduras. 
A migração da população para centros urbanos, o aumento da participação feminina no mercado de trabalho e a falta de tempo para preparo de refeições aumentaram o consumo de produtos semiprontos e principalmente dos fast food (FENIMAN, 2004). Segundo Lorenzi (1994) a mandioca de mesa tem grande potencial para aumentar sua participação nesses mercados, especialmente pela tradição de seu consumo. Cardoso (2003) relata que a médio e longo prazo, a produção de mandioca pré-cozida e congelada poderá ampliar a demanda agregada de raízes.

Buscando atender às mudanças de mercado, novos produtos alimentares estão sendo testados e inovados a fim de suprir a demanda existente. Os produtos brutos (in natura) cedem progressivamente lugar para os produtos pré-aquecidos e pré-elaborados, denominados minimamente processados (ALVES et al, 2004).

A variedade de mandioca IAC 576-70 é a bastante utilizada no estado de São Paulo devido a sua alta produtividade, bom cozimento e boas qualidades sensoriais. Sua coloração amarela facilita sua aceitação em produtos desenvolvidos como massa alimentícia, dando características organolépticas desejadas (LORENZI, 2003).

Um problema em massas alimentícias congeladas é o fenômeno da retrogradação, que ocorre devido à associação das cadeias lineares das amiloses, afetando o produto final com a formação de placas rígidas indesejáveis. Kennedy et al. (1995) relatam que as maltodextrinas são carboidratos de baixa densidade, solúveis em água e não possuem aroma de amido, sendo que em algumas aplicações são indicados para diabéticos.

O uso de maltodextrinas na indústria de alimentos está generalizado. Para Martins (2006) elas são empregadas na formulação de alimentos para bebês; como ligante em cereais matinal, em material extrusado (snaks) e em comprimidos; como veículo para adoçantes comerciais ou em mistura de condimentos; como agente dispersante em cremes; como formadores de filmes em coberturas de pílulas; como crioprotetores em sorvetes, etc.

O amido de milho ceroso ou waxy é utilizado para produção de maltodextrina, polímero de sacarídeos nutricionais devido a sua alta porcentagem de amilopectina e por ser uma fonte natural de apoio ao retardamento da retrogradação ocorrida em menor tempo nos derivados de mandioca. Germani (1981) relata que amidos cerosos com cerca de $100 \%$ de amilopectina retrogradam muito vagarosamente por causa da dificuldade com que grandes moléculas ramificadas têm de cristalizar.

O objetivo deste trabalho foi desenvolver uma massa de mandioca com características adequadas ao consumo humano, e com retrogradação reduzida em função da adição de maltodextrina de amido de milho waxy. 


\section{MATERIAL E MÉTODOS}

\subsection{Matéria-prima}

As raízes de mandioca da variedade IAC 576-70 foram coletadas na área experimental do CERAT/UNESP, localizado na Faculdade de Ciências Agronômicas, Fazenda Lageado - Botucatu-SP.

\subsection{Caracterização da matéria-prima e massa cozida}

A raiz utilizada como matéria-prima e a massa cozida, foram caracterizadas quanto as suas características físico-químicas: umidade (AOAC, 1980), matéria graxa (AOAC, “Association of Official Analytical Chemistry”, 1980), amido (SOMOGY e NELSON, 1944), fibras (AACC, 1975), cinzas (AOAC, “Association of Official Analytical Chemistry”, 1980), proteínas (AOAC, “Association of Official Analytical Chemistry”, 1980), açúcares redutores (SOMOGY, 1945 e NELSON, 1944), acidez titulável e pH (AOAC, 1980). A textura da massa de mandioca cozida (3 amostras de cada tratamento). Foram tiradas das embalagens e colocadas em copinhos de PVC de 50ml para serem submetidas á avaliação de grau de dureza (resistência a força), no aparelho texturomêtro modelo Stevens-Lfra Textura Analyser utilizando uma velocidade de $2 \mathrm{~mm} / \mathrm{s}$ e profundidade de $20 \mathrm{~mm}$ com sonda cilíndrica de acrílico tipo TA 02/1000. A unidade de medida registrada foi a g/f.cm².

\subsection{Planejamento experimental}

O delineamento experimental foi em blocos inteiramente casualizados, em esquema fatorial $4 \times 7$, com três repetições. Os tratamentos foram constituídos pela combinação de concentrações de maltodextrina adicionada à massa de mandioca ( $0,5,10$ e $15 \%$ sobre peso seco), com o tempo de armazenamento (0, 2, 4, 6, 8, 10 e 12 dias após o preparo). Foram montados dois experimentos um para armazenamento em temperatura ambiente $\pm 25^{\circ} \mathrm{C}$ e o outro sob refrigeração $10^{\circ} \mathrm{C} \pm 0,5^{\circ} \mathrm{C}$.

\subsection{Processamento e produção de massa cozida}

Foram coletadas $\pm 45 \mathrm{~kg}$ de raízes com idade de 14 meses de cultivo. As raízes foram descascadas e cortadas sendo que as pontas e a entre casca foram descartadas. A seguir as raízes foram partidas em toletes com tamanhos variando entre 5 a $7 \mathrm{~cm}$ de comprimento. Na seqüência, foram lavadas em água 
corrente (temperatura ambiente), onde foram retiradas as impurezas e sujidades, como no fluxograma da Figura 1.

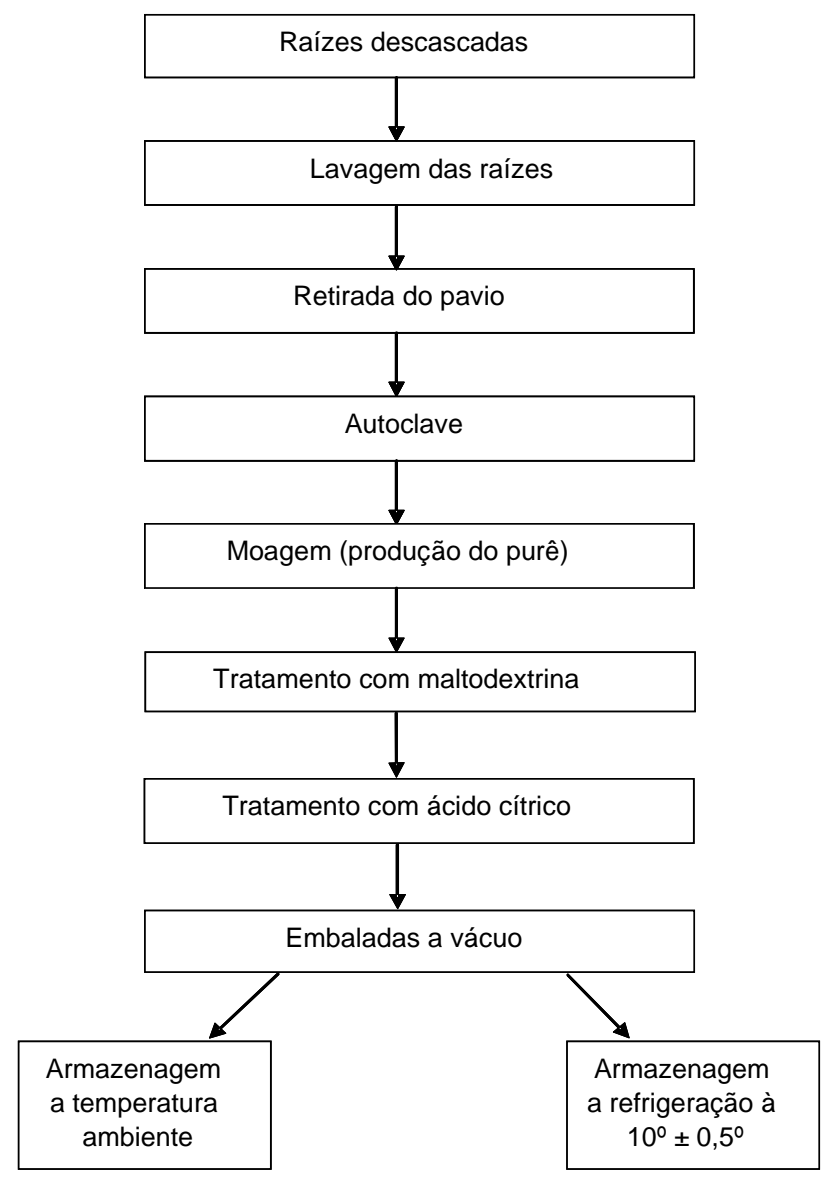

Figura 1- Fluxograma do processo de desenvolvimento da massa de mandioca e produção de corpos de prova.

Após o corte em toletes, foi retirado o pavio de cada amostra, evitando assim a presença deste material fibroso na massa. As amostras foram colocadas em becker de $500 \mathrm{~mL}$, fechadas com papel alumínio e cozidas em autoclave a $\pm 100^{\circ} \mathrm{C}$ por $40 \mathrm{~min}$. As amostras foram moídas numa amassadeira para massa de panificação.

Depois da moagem a massa foi homogeneizada no misturador do próprio moedor. Durante a homogeneização foi adicionada a maltodextrina (0, 5, 10 e 15\%) e o ácido cítrico (1\%), sobre matéria seca. 
As amostras foram embaladas a vácuo em pacotes de polietileno de dimensões 15 x 22 x 0,18 cm. Em cada pacote foram colocadas aproximadamente $100 \mathrm{~g}$ de massa.

\subsection{Análise estatística}

Os dados foram submetidos a análise de variância. As médias foram comparadas pelo teste de Tukey a 5\%, pelo programa estatístico SISVAR (FERREIRA, 2000).

\section{RESULTADOS E DISCUSSÃO}

\subsection{Caracterização da matéria-prima}

A composição físico e química (matéria seca) das raízes da mandioca IAC 576-70 estão contidas na Tabela 1.

Tabela 1- Valores médios da composição centesimal da raiz de mandioca 576-70 (\% em m.s*).

\begin{tabular}{ll}
\hline Componentes Variáveis & Valores medidos (\%) \\
\hline Umidade & 58,63 \\
Açúcar Redutor & 0,69 \\
Amido & 89,21 \\
Matéria Graxa & 0,29 \\
Cinzas & 1,33 \\
Proteína & 1,18 \\
Fibra & 2,20 \\
pH & 5,90 \\
Acidez titulável & 4,5 \\
Proteína & 1,18 \\
\hline
\end{tabular}

*m.s = matéria seca.

Os teores de umidade de 58,63\% assemelham-se aos encontrados por Grizotto \& Menezes (2003) de 57,6\% e Bezerra et al. (2002a) de 57\% em raízes 576-70 com oito meses, valores que podem estar as- 
sociados a condição de pluviosidade da área de produção agrícola. Os teores de amido, proteína, cinza, fibra pouco diferem dos valores encontrados por Feniman (2004), embora os valores de fibra, cinza e proteína estejam abaixo dos valores citados. Isto pode ocorrer em função da diferença de época de colheita da raiz, tipo de solo, adubação entre outros. Os valores de açúcar redutor e acidez estão acima dos valores encontrados por Grizotto \& Menezes (2003).

\subsection{Concentração de Açúcares Redutores (AR)}

Em condição de temperatura ambiente os valores de açúcares redutores foram afetados pelo tempo de armazenamento (Tabela 2). O valor de AR para o tempo 0 foi inferior aos demais períodos de armazenamento. Em alguns tratamentos os maiores valores de AR a partir do segundo dia de armazenamento pode estar relacionado a degradação do amido e conseqüente transformação em açúcar. Este comportamento foi observado tanto para a massa de mandioca da testemunha quanto para as dos tratamentos com maltodextrina.

Bezerra et al. (2002b) também observaram acréscimos nos teores de AR em mandiocas sob o efeito de armazenamento. Os autores observaram variação crescente de 0,2 a 1,2 g glicose $100 \mathrm{~g}^{-1}$, com o tempo de armazenamento. Os tratamentos com maltodextrina proporcionaram aumentos significativos nos teores de AR (Tabela 2). Com o aumento de AR possíveis alterações metabólicas podem ocorrer no produto, podendo assim aumentar a taxa respiratória e a atividade microbiana.

Estudos de Bezerra et al. (2002b) relatam que a embalagem proporciona um ambiente modificado e eficiente no controle da respiração das raízes, pois geralmente o teor de ácidos orgânicos diminuem com a decorrência do processo respiratório ou da conversão dos mesmos em açúcares.

Tabela 2 - Valores médios de açúcares redutores (\%) em massa de mandioca cozida com maltodextrina (waxy) em função do tempo na temperatura ambiente $\left(25^{\circ} \mathrm{C}\right)$.

\begin{tabular}{|c|c|c|c|c|}
\hline \multirow{2}{*}{ \% Waxy } & \multicolumn{4}{|c|}{ Tempo DAP (dias após o preparo) } \\
\hline & 0 & 2 & 4 & 6 \\
\hline 0 & $0,12 \mathrm{bD}$ & $0,57 \mathrm{aC}$ & $0,64 \mathrm{aC}$ & $0,66 \mathrm{aC}$ \\
\hline 5 & $0,52 \mathrm{cC}$ & $0,81 \mathrm{bBC}$ & $1,08 \mathrm{aB}$ & 0,96abB \\
\hline 10 & $0,81 \mathrm{cB}$ & $0,94 \mathrm{bcAB}$ & $1,48 \mathrm{aA}$ & $1,10 \mathrm{bB}$ \\
\hline 15 & $1,22 \mathrm{cA}$ & $1,17 \mathrm{cA}$ & $1,49 \mathrm{bA}$ & $2,52 \mathrm{aA}$ \\
\hline
\end{tabular}

Médias com a mesma letra, minúsculas nas linhas e maiúsculas nas colunas não diferem pelo teste de tukey a 5\%. 
Em ambiente refrigerado os valores de açúcares redutores também foram afetados pelo tempo de armazenamento (Tabela 3). Da mesma forma que o experimento em temperatura ambiente os produtos dos tratamentos com maltodextrina proporcionaram aumentos significativos nos teores de AR em todos os períodos de avaliação.

As maltodextrinas são utilizadas em diversos usos industriais, Cereda et al. (2002) relatam que as maltodextrinas são utilizadas como espessante ligante, substituinte de gordura, aumento de sólidos solúveis e aumenta o grau de doçura, fato este observado neste experimento.

Tabela 3 - Valores médios de açúcares redutores (\%) em massa de mandioca cozida com maltodextrina (waxy) em função do tempo em armazenamento refrigerado $\left(10^{\circ} \mathrm{C}\right)$.

\begin{tabular}{llllllll}
\hline \multirow{2}{*}{$\%$ Waxy } & Tempo (DAP) & & & & & \\
& 0 & 2 & 4 & 6 & 8 & 10 & 12 \\
\hline 0 & $0,12 \mathrm{cD}$ & $0,31 \mathrm{abcB}$ & $0,18 \mathrm{abC}$ & $0,42 \mathrm{abcC}$ & $0,38 \mathrm{abcD}$ & $0,46 \mathrm{abD}$ & $0,56 \mathrm{aD}$ \\
5 & $0,52 \mathrm{cC}$ & $0,50 \mathrm{cB}$ & $0,65 \mathrm{bcB}$ & $0,90 \mathrm{abB}$ & $1,10 \mathrm{aC}$ & $1,18 \mathrm{aC}$ & $1,16 \mathrm{aC}$ \\
10 & $0,81 \mathrm{cB}$ & $1,04 \mathrm{cA}$ & $1,66 \mathrm{bA}$ & $1,76 \mathrm{bA}$ & $1,74 \mathrm{bB}$ & $2,18 \mathrm{aB}$ & $1,71 \mathrm{bB}$ \\
15 & $1,22 \mathrm{dA}$ & $1,20 \mathrm{dA}$ & $1,75 \mathrm{cA}$ & $1,80 \mathrm{cA}$ & $2,60 \mathrm{bA}$ & $2,95 \mathrm{aA}$ & $2,41 \mathrm{bA}$ \\
\hline
\end{tabular}

Médias com a mesma letra, minúsculas nas linhas e maiúsculas nas colunas não diferem pelo teste de tukey a 5\%.

\subsection{Valor de pH}

Quando armazenado sob temperatura ambiente, apresentou menor valor de $\mathrm{pH}$ para o tempo 0 e a massa obtida com o tratamento testemunha (sem maltodextrina). Nos demais tratamentos não houveram diferenças no pH em decorrência do tempo de armazenamento (Tabela 4). Resultados diferentes foram observados por Bezerra et al. (2002b) com acréscimo inicial do valor de pH e posterior diminuição para as raízes minimamente processadas com o tempo de armazenamento.

$\mathrm{Na}$ estocagem refrigerada o valor de $\mathrm{pH}$ também foi menor para o tempo 0 , porém neste caso os menores valores foram observados em todos os tratamentos (Tabela 5), enquanto que em temperatura ambiente o menor valor havia sido observado apenas para a testemunha (sem maltodextrina). Com a adição de maltodextrina houve alterações significativas do pH apenas no tempo 0 e 2 DAP (dias após o preparo), nestes casos os menores valores foram observados na testemunha. A partir do segundo dia de armazenamento não houve diferença, independente da porcentagem de maltodextrina utilizada. Isto mostra que a refrigeração aliada a embalagem a vácuo foram eficientes para evitar a acidificação da pasta de mandio- 
ca. Os valores de AR aumentaram no decorrer dos dias e da concentração de maltodextrina, contudo o pH não sofreu alterações significativas, não acidificando o produto as diferentes concentrações de AR.

Tabela 4 - Valores médios de pH na massa de mandioca cozida com maltodextrina (waxy) em função do tempo na temperatura ambiente.

\begin{tabular}{lllll}
\hline \% Waxy & Tempo (DAP) & & & \\
& 0 & 2 & 4 & 6 \\
\hline 0 & $3,67 \mathrm{bA}$ & $4,36 \mathrm{aA}$ & $4,41 \mathrm{aA}$ & $4,11 \mathrm{aA}$ \\
5 & $4,07 \mathrm{aA}$ & $4,29 \mathrm{aA}$ & $4,32 \mathrm{aA}$ & $4,07 \mathrm{aA}$ \\
10 & $4,05 \mathrm{aA}$ & $4,27 \mathrm{aA}$ & $4,20 \mathrm{aA}$ & $4,10 \mathrm{aA}$ \\
15 & $3,87 \mathrm{aA}$ & $4,28 \mathrm{aA}$ & $4,21 \mathrm{aA}$ & $4,10 \mathrm{aA}$
\end{tabular}

Médias com a mesma letra, minúsculas nas linhas e maiúsculas nas colunas não diferem pelo teste de tukey a 5\%.

Tabela 5 - Valores médios de pH na massa de mandioca cozida com maltodextrina (waxy) em função do tempo em ambiente refrigerado $\left(10^{\circ} \mathrm{C}\right)$.

\begin{tabular}{|c|c|c|c|c|c|c|c|}
\hline \multirow{2}{*}{ \% Waxy } & \multicolumn{7}{|c|}{ Tempo (DAP) } \\
\hline & 0 & 2 & 4 & 6 & 8 & 10 & 12 \\
\hline 0 & $3,67 \mathrm{bB}$ & 4,10abC & $4,45 \mathrm{aA}$ & $4,30 \mathrm{aA}$ & $4,25 a A$ & $4,30 \mathrm{aA}$ & $4,28 \mathrm{aA}$ \\
\hline 5 & 4,07bA & 4,34abAB & $4,55 \mathrm{aA}$ & 4,35abA & 4,47abA & 4,50abA & 4,42abA \\
\hline 10 & $3,05 \mathrm{bC}$ & $4,52 \mathrm{aA}$ & $4,71 \mathrm{aA}$ & $4,48 \mathrm{aA}$ & $4,60 \mathrm{aA}$ & 4,60aA & $4,52 \mathrm{aA}$ \\
\hline 15 & 3,87bAB & 4,36aAB & 4,59aA & 4,42aA & 4,42aA & 4,46aA & 4,48aA \\
\hline
\end{tabular}

Médias com a mesma letra, minúsculas nas linhas e maiúsculas nas colunas não diferem pelo teste de tukey a 5\%.

\subsection{Acidez titulável (AT)}

Em condição ambiente a AT apresentou aumento significativo no decorrer do tempo de armazenamento para todas as concentrações de maltodextrina (Tabela 6). O aumento da AT com o passar do tempo de armazenamento é conseqüência das reações bioquímicas e microbiológicas no material, assim como na diminuição do pH. Bezerra et al. (2002b) também verificaram a redução do pH e um aumento do AT em raízes minimamente processadas em condição de armazenamento ambiente. O aumento da AT no último dia de avaliação pode estar associado com a ação microbiológica. 
Em condição refrigerada a AT foi menor no tempo 0. A partir de 2 DAP até 10 DAP não houve diferença. Aos 12 DAP os valores decresceram (Tabela 7). Assim como no AR também ocorreu um decline no final dos dias de armazenamento em refrigeração ocasionado assim condição favorável microbiológica.

O ligeiro aumento nos teores de acidez nas massas cozidas em condição refrigerada, possivelmente está relacionado ao início do processo fermentativo, que segundo Bezerra et al. (2002), é ocasionado por bactérias anaeróbias facultativas, capazes de consumir oxigênio e produzir ácidos orgânicos como o lático, butírico, acético, entre outros.

Alves et al (2004) também observaram aumento e logo após decréscimo dos valores de AT, seguidas de elevações de $\mathrm{pH}$, em mandiocas minimante processadas seladas a vácuo e condicionadas sob refrigeração.

Tabela 6 - Valores AT (\%) na massa de mandioca cozida com maltodextrina (waxy) em função do tempo na temperatura ambiente.

\begin{tabular}{lllll}
\hline \multirow{2}{*}{$\%$ Waxy } & \multicolumn{2}{l}{ Tempo de estocagem DAP } & & \\
& 0 & 2 & 4 & 6 \\
\hline 0 & $4,22 \mathrm{cA}$ & $4,50 \mathrm{cB}$ & $6,90 \mathrm{bB}$ & $11,67 \mathrm{aA}$ \\
5 & $4,30 \mathrm{dA}$ & $6,03 \mathrm{cA}$ & $8,33 \mathrm{bA}$ & $12,17 \mathrm{aA}$ \\
10 & $4,26 \mathrm{dA}$ & $6,30 \mathrm{cA}$ & $8,30 \mathrm{bA}$ & $11,87 \mathrm{aA}$ \\
15 & $4,52 \mathrm{dA}$ & $6,67 \mathrm{cA}$ & $8,83 \mathrm{bA}$ & $12,37 \mathrm{aA}$ \\
\hline
\end{tabular}

Médias com a mesma letra, minúsculas nas linhas e maiúsculas nas colunas não diferem pelo teste de tukey a 5\%.

Tabela 7 - Valores AT (\%) na massa de mandioca cozida com maltodextrina (waxy) em função do tempo em ambiente refrigerado $\left(10^{\circ} \mathrm{C}\right)$.

\begin{tabular}{llllllll}
\hline \multirow{2}{*}{ \% Waxy } & \multicolumn{2}{l}{ Tempo DAP } & \multicolumn{6}{c}{} & & & & & \\
& 0 & 2 & 4 & 6 & 8 & 10 & 12 \\
\hline 0 & $4,22 \mathrm{cA}$ & $4,1 \mathrm{cB}$ & $5,4 \mathrm{bA}$ & $6,0 \mathrm{abAB}$ & $6,60 \mathrm{aA}$ & $6,32 \mathrm{aAB}$ & $6,03 \mathrm{abA}$ \\
5 & $4,30 \mathrm{bA}$ & $6,06 \mathrm{aA}$ & $5,50 \mathrm{aA}$ & $5,80 \mathrm{aB}$ & $5,80 \mathrm{aB}$ & $5,80 \mathrm{aB}$ & $4,17 \mathrm{bB}$ \\
10 & $4,26 \mathrm{bcA}$ & $5,50 \mathrm{aA}$ & $5,33 \mathrm{aA}$ & $5,33 \mathrm{aB}$ & $5,0 \mathrm{abC}$ & $5,0 \mathrm{abC}$ & $4,0 \mathrm{cB}$ \\
15 & $4,52 \mathrm{bA}$ & $6,0 \mathrm{aA}$ & $5,83 \mathrm{aA}$ & $6,57 \mathrm{aA}$ & $6,13 \mathrm{aAB}$ & $6,58 \mathrm{aA}$ & $4,67 \mathrm{bB}$ \\
\hline
\end{tabular}

Médias com a mesma letra, minúsculas nas linhas e maiúsculas nas colunas não diferem pelo teste de tukey a 5\%. 


\subsection{Teor de umidade}

A adição de maltodextrina também não interferiu neste parâmetro. Em temperatura ambiente as umidades das massas não foram influenciadas pelo armazenamento. Alves et al. (2004) também não observaram diferenças entre os teores de umidade de raízes minimamente processadas. Os autores verificaram que nos tratamentos selados a vácuo os índices de perda de umidade são mínimos. O teor médio de umidade em condição ambiente das amostras neste trabalho foi de 54,5\%, valor abaixo do encontrado por Bezerra (2000) de 57,01\%. Essa diferença pode estar relacionada à diferença de idade das raízes colhidas.

Em relação à umidade em ambiente refrigerado também não houveram diferenças significativas entre os dias de armazenamento e nem em função dos tratamentos com maltodextrina. Assim como na condição de temperatura ambiente houve pouca variação dos valores.

Segundo Carvalho et al. (1982), o teor de água é um dos aspectos mais importantes da conservação de raízes pela influência direta na durabilidade das mesmas, pois cultivares resistentes à deterioração fisiológica apresentam maiores teores de umidade.

\subsection{Análise de textura}

A análise de textura (dureza) em condição de armazenagem ambiente mostrou diferenças significativas para todos o fator avaliado (Tabela 8). As texturas verificadas na massa de mandioca cozida em temperatura ambiente tiveram comportamento constante, com aumento do grau de força exercido $\left(\mathrm{g} / \mathrm{f} . \mathrm{cm}^{2}\right)$ com o passar dos dias. Também foi verificado que com o aumento das concentrações de maltodextrina, os valores da textura eram menores em relação à testemunha no decorrer dos dias.

Nas amostras armazenadas em temperatura refrigerada (Tabela 9), a textura alcançou valores maiores quando comparados á condição ambiente, mostrando que a condição refrigerada proporcionou uma reorganização das estruturas químicas dos polissacarídeos amiloses e amilopectinas na massa dando a ele um aspecto endurecido. Enquanto os valores da textura das amostras em condição ambiente variava entre 87 a 422 (g/f.cm²), as massas em condição de refrigeração estavam entre 228 a 990 (g/f). Esse endurecimento está relacionado com o condicionamento a frio, em consequência da tendência a retrogradação da massa com o passar dos dias, sendo esse processo amenizado com maiores concentrações de maltodextrinas de amido de milho waxy.

Trabalho realizado por Berbari (2000) mostrou que o congelamento e a pré-fritura mais congelamento, para os palitos de polpa de mandioca, não provocaram alterações que pudessem ser detectadas pela avaliação objetiva da textura. As amostras de mandioca com maltodextrinas apresentaram aumento na avaliação de dureza; contudo notou-se que tanto no condicionamento refrigerado como no ambiente, a- 
mostras adicionadas de 15\% de maltodextrina demonstraram menores índices de dureza comparados a tratamentos com menores porcentagens.

Em ambiente refrigerado as massas apresentam uma maior durabilidade, contudo um endurecimento maior na massa processada, como ocorrido com os teores de açucares redutores. Salienta-se que a massa de mandioca pode ser armazenada em condição ambiente, desde que se ajuste a quantidade adequada de aditivos para prolongar o tempo de conservação.

Tabela 8 - Valores médios da textura (g/f) nas amostras de massa de mandioca cozida nos tratamentos com maltodextrina (waxy) em função do tempo na temperatura ambiente.

\begin{tabular}{lllll}
\hline$\%$ Waxy & \multicolumn{2}{c}{ Tempo de estocagem DAP } & & \\
& 0 & 2 & 4 & 6 \\
\hline 0 & $109 \mathrm{bA}$ & $361 \mathrm{aA}$ & $427 \mathrm{aA}$ & $423 \mathrm{aA}$ \\
5 & $99 \mathrm{cA}$ & $268 \mathrm{bB}$ & $345 \mathrm{abA}$ & $390 \mathrm{aA}$ \\
10 & $96 \mathrm{cA}$ & $197 \mathrm{bB}$ & $233 \mathrm{bB}$ & $341 \mathrm{aAB}$ \\
15 & $95 \mathrm{bA}$ & $129 \mathrm{bB}$ & $228 \mathrm{aB}$ & $268 \mathrm{a} \mathrm{B}$ \\
\hline
\end{tabular}

Médias com a mesma letra, minúsculas nas linhas e maiúsculas nas colunas não diferem pelo teste de tukey a 5\%.

Tabela 9 - Valores médios da textura (g/f) nas amostras de massa de mandioca cozida nos tratamentos com maltodextrina (waxy) em função do tempo em ambiente refrigerado $\left(10^{\circ} \mathrm{C}\right)$.

\begin{tabular}{|c|c|c|c|c|c|c|c|}
\hline \multirow[t]{2}{*}{ \% Waxy } & \multicolumn{7}{|c|}{ Tempo de estocagem DAP } \\
\hline & 0 & 2 & 4 & 6 & 8 & 10 & 12 \\
\hline 0 & $109 \mathrm{dA}$ & 361dA & 799cA & 886abcA & 829bcA & 944abA & $990 \mathrm{aA}$ \\
\hline 5 & $99 \mathrm{cAB}$ & 268cAB & 637bB & 771aB & 771aAB & 869aAB & $845 \mathrm{aBC}$ \\
\hline 10 & $96 \mathrm{~dB}$ & $233 \mathrm{~dB}$ & $615 \mathrm{cB}$ & 698bcB & 714bcC & 767bC & $945 \mathrm{aAB}$ \\
\hline 15 & $95 \mathrm{eB}$ & $228 \mathrm{eB}$ & $445 \mathrm{dC}$ & $505 \mathrm{cdC}$ & $586 \mathrm{bcD}$ & $644 \mathrm{bD}$ & 764aD \\
\hline
\end{tabular}

Médias com a mesma letra, minúsculas nas linhas e maiúsculas nas colunas não diferem pelo teste de tukey a 5\%.

\subsection{Análise microbiológica}

Os resultados mostraram que os valores encontrados (Tabela 10) para contagem padrão em placa (bactérias mesófilas) e bolores e leveduras estão dentro dos padrões aceitáveis pela legislação do Ministério da Agricultura (BRASIL, 2001). Aos 15 DAP para as amostras armazenadas sob refrigeração o NMP/g de microorganismos aumentaram, ficando dentro dos limites de aceitabilidade propostos pela RDC ${ }^{\circ} 12$ 
de 2 de janeiro de 2001 (raízes, tubérculos e similares branqueados ou cozidos, inteiros ou picados, estáveis a temperatura ambiente, refrigerados ou congelados para consumo direto).

Observa-se na Tabela 10 que a contagem de coliformes totais $\left(35^{\circ} \mathrm{C}\right)$ e termotolerante $\left(45^{\circ} \mathrm{C}\right)$ foram isento em $25 \mathrm{~g}$ estando dentro dos padrões exigidos pela legislação do Ministério da Agricultura (BRASIL, 2001). Nas amostras armazenadas em temperatura ambiente aos sete DAP a proliferação microbiológica foi visivelmente alta, sendo necessário o descarte das amostras.

A baixa atividade microbiológica, determinada através dos parâmetros estudados, poderia ser atribuída a alguns fatores, como: o baixo nível de contaminação das amostras durante o processamento, manipulação e armazenamento; como também a temperatura de armazenamento das massas.

Tabela 10 - Análises microbiológicas na massa de mandioca (em UFC/g) no 0 e 15 DAP em armazenagem refrigerado.

\begin{tabular}{l|lll}
\hline DAP & Contagem Total & $\begin{array}{l}\text { Contagem Bolores } \\
\text { Leveduras }\end{array}$ & $\begin{array}{l}\text { Coliformes Termoto- } \\
\text { lerante e Totais }\end{array}$ \\
\hline 0 & 1.3 & 0,1 & Isento em 25g \\
$\mathbf{1 5}$ & 4,3 & 2,5 & Isento em 25g \\
\hline
\end{tabular}

\section{CONCLUSÕES}

A adição da maior concentração de maltodextrina de amido de milho waxy (no caso os 15\%) na massa de mandioca processada, resultou numa maior eficiência no controle a dureza no decorrer dos dias.

A adição de maltodextrinas nas amostras aumentaram os teores de açúcares redutores, favorecendo um ambiente de crescimento microbiológico.

A massa alimentícia de mandioca com adição de maltodextrina (waxy) é um produto de fácil elaboração, apresentando viabilidade para ser produzida em escala industrial. 


\section{REFERÊNCIAS}

AACC. AMERICAN ASSOCIATION OF CEREAL CHEMISTS. Approved methods of the American Associantin of Cereal Chemists, St. Paul, 1975.

ALVES, A. et al. Alterações na qualidade de raízes de mandioca (manihot esculenta crantz) minimamente processadas. Ciência Agrotécnica, Lavras, v. 29, n. 2, p. 330-337, mar./abr. 2004.

AOAC. ASSOCIATION OF OFFICIAL AGRICULTURAL CHEMISTS. Official methods of analysis of the association of official chemists. 12th ed. Washington, dc, 1975. p. 1094.

BRASIL. AGENCIA NACIONAL DE VIGILÂNCIA SANITÁRIA. Resolução RDC n. 12, de 10 de janeiro de 2001. Diário Oficial União, Brasília, 10 janeiro, 2001.

BERBARI, S. A. G. Desenvolvimento de tecnologia para obtenção de produto formatado e congelado de mandioca. 2001, p. 123. Tese (Doutorado em Tecnologia de Alimentos). Faculdade de Engenharia de Alimentos. Universidade de Campinas, 2001.

BEZERRA, V. S. Alterações na composição química e cocção de raízes de mandioca (Manihot esculenta Crantz) minimamente processadas. 2000. p. 92. Dissertação em Ciência dos Alimentos. Universidade Federal de Lavras, Lavras, MG, UFLA, 2000.

BEZERRA, V. S. et al. Processamento mínimo em mandioca: alterações na qualidade e componentes nutricionais. In: CONGRESSOS BRASILEIROS DE CIÊNCIA E TECNOLOGIA DE ALIMENTOS, p. 18, 2002, Porto Alegre, RS. Anais... Porto Alegre, 2002a.

BEZERRA, V. S. Raízes de mandioca minimamente processadas: efeito do branqueamento na qualidade e na conservação. Ciência Agrotécnica, Lavras, n.3, p.564-575, 2002b.

CARDOSO, C. E. L. Competitividade e inovação tecnológica na cadeia agroindustrial de fécula de mandioca no Brasil. 2003. p. 188. Tese (Doutorado em Ciências) Escola Superior de Agricultura Luiz de Queiroz, Universidade de São Paulo, Piracicaba, 2003. 
CARVALHO, V. D. de; CHALFOUN, S. M.; JUSTE JÚNIOR, E. S. G. Armazenamento pós-colheita da mandioca: II. efeito das alterações no grau de deterioração fisiológica e na composição físico-química e química de seis cultivares de mandioca. Revista Brasileira de Mandioca, Cruz das Almas, v. 1, n. 1, p. 23-34, 1982.

CEREDA, M. P. Propriedades gerais do amido. São Paulo: Fundação Cargill, p. 224, 2002.

CUENCA, M. A. G.; MANDARINO, D. C.; Aspectos agroeconômicos da cultura da mandioca: características e evolução da cultura no Estado de Sergipe entre 1990 e 2004. Aracaju, SE, EMBRAPA. Centro de Pesquisa Agropecuária dos Tabuleiros Costeiros, p. 21, 2006.

FENIMAN, C. M.; Caracterização de raízes de mandioca (Manihot esculenta Crantz) do cultivar 57670 quanto á coç̧ão, composição química e propriedades do amido em duas épocas de colheitas. 2004, p. 99. Dissertação (Mestrado em Ciência e Tecnologia de Alimento) Escola Superior de Agricultura Luiz de Queiroz, Universidade de São Paulo, Piracicaba, 2004.

FERREIRA, D. F. Análise estatística por meio do SISVAR (Sistema para Análise de Variância) para Windows versão 4.0. In: REUNIÃO ANUAL DA REGIÃO BRASILEIRA DA SOCIEDADE INTERNACIONAL DE BIOMETRIA, 45, São Carlos, 2000. Anais. Universidade Federal de São Carlos, 2000. p.255-258.

GERMANI, R. Retrogradação de géis de amido de milho: Influência de açucares, lipídeos e tipos de amido. 1981. Campinas, p. 122. Tese (Doutorado em Tecnologia de Alimentos). Faculdade de Engenharia de Alimentos. Universidade de Campinas, 1981.

GRIZOTTO, R.K.; MENEZES, H.C. Avaliação da aceitação de “chips” de mandioca. Ciência e Tecnologia de Alimentos, n. 23, p.79-86, dezembro, 2003. Campinas, SP.

KENNEDY, J.F.; KNILL, C.J.; TAYLOR, D.W. Maltodextrins. In: KEARSLEY, M.W.; DZIEDZIC, S.Z. Blackie Academic \& Professional, p.65-82, 1995.

LORENZI, J. O. MANDIOCA. Campinas: CATI, 2003. p. 116. Boletim técnico. 
LORENZI, J.O.; Variação na qualidade culinária das raízes de mandioca. "International Meeting on Cassava Flour and Starch", Cali, Colômbia, janeiro de 1994. Bragantia, Campinas-SP. V. 52(2), p.237-245, 1994.

MARTINS, P. C. Estudo da influência de uma fase lipídica na aglomeração de pós alimentícios.

2006. Campinas, p. 178. Tese (Doutorado em Engenharia de Processos). Faculdade de Engenharia de Alimentos. Universidade de Campinas, 2006.

NELSON, N. A. Photometric adaptation of the somogy method for the determination of glucose. Journal Biology Chemists, Baltimore, n. 153, p. 375-380, 1944.

SOMOGY, M. Detemination of blood sugar. Journal Biological. Chemistry, Baltimore, n. 160, p. 69-73. 1945. 